\title{
Dificuldades de aprendizagem em itens de uma prova de Didática Geral de futuros professores
}

\author{
Isauro Beltrán Núñez* \\ Universidade Federal do Rio Grande do Norte \\ Betania Leite Ramalho** \\ Universidade Federal do Rio Grande do Norte
}

Resumo No presente estudo, são apresentados os erros e as dificuldades de aprendizagem a eles associadas, detectados em respostas de futuros professores do ensino fundamental em itens de conhecimentos da Didática Geral numa prova de um concurso públiço. A metodologia utilizada foi a análise de desempenho e de erros (NÚÑEZ \& RAMALHO, 2012), associando-se possíveis dificuldades de aprendizagem que podem explicar a ocorrência desses erros. Os dados empíricos foram fornecidos pela Comissão Permanente de Concursos da UFRN (Comperve/UFRN). Os resultados evidenciam um baixo desempenho nas questões da prova e revelam erros e dificuldades relacionados ao objeto da Didática Crítica, aos fundamentos do ensino com base nas ideias da escola Histórico Cultural de L. S. Vigotsky, à organização dos conteúdos e à formação de atitudes, entre outras. Esses resultados podem ser referência para se pensar a formação inicial dos professores em relação ao conhecimento profissional da Didática Geral como dimensão essencial da futura atividade de ensino nas escolas.

PALAVRAS-CHAVE: Didática Geral; Avaliação; Dificuldades de aprendizagem. 


\section{Learning difficulties in General Didactics test items of future primary school teachers}

Abstract This study aims to present the errors and associated learning difficulties, detected in the answers of future primary teachers in items in General Didactics knowledge in a public test. Methodology used was the performance and error analysis (NÚÑEZ \& RAMALHO, 2012), associating possible learning difficulties that may explain the occurrence of these errors. Empirical data were provided by the UFRN Comissão Permanente de Concursos da UFRN (Comperve/UFRN). Results have shown a poor performance in the test questions and revealed errors and difficulties related to the object of Critical Didactics and fundamentals of teaching based on the ideas of the Cultural Historical School of L.S. Vigotsky, to the organization of contents and the formation of attitudes, among others. These results can be a reference for thinking about the initial formation of teachers in relation to the professional knowledge of General Didactics as an essential dimension of future teaching activity in schools.

KEYWORDS: General Didactics; Evaluation; Learning difficulties.

\section{Introdução}

$\mathrm{Na}$ formação inicial dos professores para a Educação Básica, a Didática tem como função primordial ser um espaço para pensar, organizar e desenvolver o currículo e o ensino dos estudantes na escola. Portanto, o conhecimento profissional dos professores sobre Didática Geral constitui-se em conhecimento estratégico, essencial para a prática docente, e, consequentemente, para sua formação.

A Didática Geral concentra diferentes conhecimentos profissionais e é referência para questionamentos acerca das teorias sobre aprendizagem e ensino. Ademais, aproxima os "modelos didáticos implícitos" daqueles desejados na formação, para modificar, quando necessário, os "modelos espontâneos". Essa transição supõe conscientizar os professores sobre a compreensão do ensino fundamentado nos conhecimentos científicos da profissão docente.

O panorama da Didática e suas implicações na formação docente tem sido estudado por vários autores, entre eles Libâneo (2010); Gatti (2010); Longarezi; Puentes (2011); Candau (2009). Para esses autores, a formação didática docente é uma exigência para superar o descompasso entre o processo de ensino e o de aprendizagem no contexto escolar. Embora reconheçam a complexidade da problemática da não aprendizagem dos estudantes, tais autores consideram que um dos fatores que evidentemente incide no ensino é a fragilidade da formação didática docente.

A fim de contribuir para um ensino de qualidade, direito dos estudantes, objetivando uma educação que forme cidadãos conscientes, críticos, comprometidos 
com uma sociedade democrática e justa, o professor deve ter uma formação profissional fundamentada em sólidos conhecimentos, saberes e competências para o ensino, entre os quais os de Didática Geral têm lugar significativo.

Neste trabalho, apresentam-se resultados de um estudo cujo objetivo era caracterizar o conhecimento profissional sobre Didática Geral, para o início da atividade profissional de licenciados em diferentes componentes curriculares, no contexto de um concurso público para professor do Ensino Fundamental. A partir desse objetivo, foram propostas como questões de estudo:

a) qual o desempenho dos futuros professores nas questões de uma prova de Didática Geral de um concurso público para o cargo de professor do ensino fundamental?

b) quais erros e dificuldades de aprendizagem são evidências do conhecimento da Didática Geral dos futuros professores na prova?

Realizou-se o estudo do conhecimento profissional pelas análises do desempenho nas questões da prova e pelos erros que refletem determinadas dificuldades de aprendizagem da Didática Geral por considerarmos os erros como um determinado tipo de conhecimento.

\section{Conhecimento profissional da Didática Geral dos professo- res do ensino fundamental}

Os estudos sobre o conhecimento dos professores para ensinar têm sido também focalizados sob a orientação da profissionalização da docência (SHULMAN, 1987; MARCELO, 2012; TARDIF, 2003; GAUTHIER et al., 1998; PIMENTA, 1997; PUENTES et al., 2009; RAMALHO; NÚNEZ; GAUTHIER, 2004). Essas pesquisas estudaram como os professores aprendem a ensinar e quais conhecimentos, saberes e competências são necessários para a prática docente como atividade profissional, o que interfere nos processos de formação e de profissionalização docentes.

Nessa perspectiva, o conhecimento da Didática Geral é essencial para a atividade profissional. Libâneo (2002) expõe que é papel do professor planejar, selecionar e organizar conteúdos, estruturar tarefas, criar condições de estudo, motivar os estudantes, ou seja, dirigir as atividades de aprendizagem para que os estudantes tornem-se sujeitos ativos da própria aprendizagem.

A Didática é um campo disciplinar que tem como objeto de estudo o processo docente-educativo em que se expressam dialeticamente duas dimensões: uma voltada ao objeto das Didáticas Específicas, e outra, ao da Didática Geral, cuja tendência é estabelecer relações interdisciplinares para uma compreensão holística do processo, que responde à necessidade de coordenar e planejar as ações entre as diferentes disciplinas do currículo. Essas, portanto, apresentam diferentes perspectivas conceituais e metodológicas (SALAZAR, 2004).

O professor deve mobilizar criativamente não só o conhecimento da disciplina que ensina como também outros que integram o que Shulman (1987) chama de 
Base de Conhecimento da Profissão Docente. Dentre estes, situa-se o Conhecimento Didático, que contribui para garantir a aprendizagem e o desenvolvimento dos estudantes no contexto da escola.

O Parecer CNE/CP a/2001, (BRASIL, 2001) considera como conhecimentos básicos da formação profissional de professores da educação básica: currículo e desenvolvimento curricular, transposição didática, contrato didático, planejamento, organização do tempo e do espaço, gestão de classe, integração grupal, criação, realização e avaliação das situações didáticas, avaliação de aprendizagem dos alunos, dificuldades e trabalho diversificado, relação professor-aluno, análise de situações educativas e de ensino complexas, entre outros. Assim, estabelecem-se conteúdos importantes da Didática Geral na formação inicial docente.

Zabalza (1990) entende que a Didática Geral deve ocupar-se de conhecimentos e habilidades dos professores para poder tomar decisão em face de um conjunto de situações-problema de ensino. Dentre estes, destaca: ensino, planejamento e desenvolvimento do currículo, processos de aprendizagem, desenho de inovações, novas tecnologias educativas e programas especiais de ensino.

Libâneo (2002) destaca como elementos constitutivos da Didática Geral, segundo a definição dos objetivos gerais e específicos, um conjunto de conhecimentos sistematizados pelas seguintes disciplinas: Filosofia da Educação, Teoria da Educação, Teoria do Conhecimento e Antropologia. São esses conhecimentos que estruturam conteúdos que fundamentam o amplo campo de inserção da Didática: métodos de investigação da ciência ensinada, adequação às idades, ao nível de desenvolvimento mental dos alunos, aos processos internos de assimilação, aos processos de desenvolvimento da linguagem, aos significados sociais do conhecimento. Dada sua natureza, observa-se que se tratam de conhecimentos associados às categorias professor e aluno, como a Filosofia, a Psicologia, a Sociologia, a Linguística, a Psicopedagogia e a Sociolinguística, e conhecimentos relativos aos métodos de ensino, Teoria do Conhecimento, Psicologia, Linguística, Teoria da Comunicação, etc.

Além desses conhecimentos estruturantes da Didática Geral, Libâneo (2002) considera importante incluir outros que se tornaram essenciais para dar coerência e atender às demandas da escola do século XXI, entre eles: ensino do pensar e do aprender, transversalidade das culturas, processos comunicativos e trabalho interativo, novas tecnologias da informação e da comunicação, cultura organizacional, interdisciplinaridade e avaliação institucional e da aprendizagem.

Visto que a Didática Geral está intimamente ligada às tendências pedagógicas e às teorias do currículo, não se pode deixar de considerar, na atual configuração dos conhecimentos da Didática Geral, as contribuições da Pedagogia Crítica e das Teorias Críticas e Pós-Críticas do Currículo. Dentre estes, Candau (2009) e Libâneo (2002) ressaltam: Razão e Consciência Individual; Noção de Ciência e Conteúdo Escolar; Sociedade do Conhecimento e da Informação; Qualidade da Educação; Valores, Objetivos da Educação e a crise da noção de Totalidade; Cultura, Poder e Currículo; Educação e Linguagem; Ensino Crítico e Questões Éticas; Multiculturalismo, Inclusão Social, Diversidade, Gênero, Identidade, dentre outros (CANDAU, 2009). 


\section{Situando o estudo}

O presente artigo toma como objeto de estudo a prova de Didática Geral (10 questões) de um concurso público, realizado no Estado do Rio Grande do Norte, em 2015, para provimento de cargo de professores do ensino fundamental. Os dados sobre o desempenho dos candidatos na prova em estudo foram fornecidos pela Núcleo Permanente de Concursos da UFRN (COMPERVE).

Participaram desse concurso 12.232 candidatos, dos quais $65 \%$ se formaram em instituições de ensino superior privado e $35 \%$ em instituições públicas. Do total, $76,7 \%$ declararam-se do sexo feminino e $23,2 \%$ do masculino, fato típico do magistério nesse nível de escolaridade. Há um expressivo engajamento (71,3\%), a maioria dos candidatos (45,0\%) estão entre 26 e 35 anos e apenas $27,4 \%$ estão na faixa de mais de 40 anos, na maioria (75\%) recém-graduados, ou seja, tinham concluído a formação superior em menos de cinco anos.

Os sujeitos do estudo serão chamamos de futuros professores ou candidatos, por serem aspirantes ao cargo de professor do ensino fundamental.

\section{Metodologia da pesquisa}

A pesquisa, de natureza descritiva e exploratória, está fundamentada na metodologia de análises de erros (NÚÑEZ; RAMALHO, 2012) e na análise de desempenho, segundo a teoria clássica de itens (PASQUALI, 2013), vias escolhidas para se inferir os erros e, consequentemente, o conhecimento profissional docente em questão. O número expressivo e a forma de representação de dados conferem ao estudo tanto uma dimensão quantitativa, expressa nas análises estatísticas descritivas, assim como qualitativa, quando leva a reconhecer a postura epistemológica da existência de múltiplas realidades construídas, ao se dar sentido e significado aos dados, o que depende das posturas filosóficas, teóricas, ontológicas e praxiológicas dos pesquisadores.

As questões são de natureza objetiva, do tipo múltipla escolha, com a seguinte estrutura: a) um texto base, contextualizado, no qual se apresenta a situação -problema vinculada à futura atividade docente dos candidatos; b) um enunciado, que apresenta clara e objetivamente a tarefa cognitiva a ser realizada, completa a situação-problema e articula o enunciado à alternativas de respostas e c) as alternativas de respostas, uma correta (gabarito) e 03 incorretas (distratores). Cada item responde a uma dada habilidade na qual se mobilizam os conhecimentos da Didática Geral para solução do problema apresentado (BRASIL, INEP, 2015).

As questões foram elaboradas a partir de um programa baseado em conteúdos e habilidades necessários ao início da atividade profissional. A análise considera a habilidade/conteúdo focalizada para poder estabelecer relações entre a opção correta e as incorretas.

A resposta à primeira pergunta de estudo se fundamenta nas análises do desempenho dos candidatos fornecidas pela Comperve, tomando como referência o Índice de desempenho ou de Acerto, que expressa o percentual de candidatos que 
acertam o gabarito da questão, o que é também uma medida do grau de dificuldade (HALADYNA, 2004). Para dimensionar essa categoria, foram utilizadas subcategorias que são estabelecidas em índices de desempenho, apresentados na Tabela 1.

Tabela 1 - Subcategorias do índice de desempenho

\begin{tabular}{c|c}
\hline Índice de Desempenho & \% de acerto \\
\hline Muito alto & $75-100$ \\
\hline Alto & $55-74$ \\
\hline Médio & $45-54$ \\
\hline Baixo & $25-44$ \\
\hline Muito baixo & $0-24$ \\
\hline
\end{tabular}

Fonte: UFRN - COMPERVE (2017).

Para caracterizar os conhecimentos profissionais, foram feitas análises de erros, relacionando-os às dificuldades de aprendizagem como hipóteses explicativas para os erros. O Erro é compreendido, neste estudo, como uma diferença entre aquilo que se conhece e aquilo que é determinado por um dado campo disciplinar (conhecimento desejável), ou seja, é a expressão do desvio da resposta escolhida em relação a um modelo de resposta considerado como correto na Didática Geral (NÚÑ̃EZ, 2009). Dessa forma, os erros são evidenciados quando o candidato escolhe uma alternativa considerada um distrator, ou seja, uma opção de resposta tida como errada (NÚÑEZ; RAMALHO, 2012). Cada um dos distratores foi elaborado de forma a estar associado a um ou mais erros conceituais, os quais podem estar relacionados, por sua vez, a determinadas dificuldades de aprendizagem. A caracterização do erro é feita a partir de um diálogo crítico com o referencial teórico, assumido como correto, uma vez que os erros sempre são relativos.

Dificuldade de aprendizagem é um termo polissêmico que abrange um grupo heterogêneo de problemas capazes de alterar as possibilidades de aprendizagem de uma pessoa, influenciados por diversos fatores relacionados à família, à escola e ao próprio estudante. A dificuldade de aprendizagem, neste estudo, é entendida como aquilo que leva ao erro. Desse modo, podem ser estabelecidas relações causais entre o erro e a dificuldade de aprendizagem (NÚÑEZ; RAMALHO, 2012).

Os erros se evidenciam na escolha dos distratores, são de natureza fenomenológica, enquanto as dificuldades de aprendizagem constituem-se em hipótese explicativa, pois representam um dado nível de essência do conhecimento disciplinar, numa relação dialética de essência-fenômeno. Nessa perspectiva, não é possível estabelecer uma relação unívoca entre os erros, as dificuldades de aprendizagem e o conhecimento disciplinar da Didática Geral, embora se reconheça uma importante correlação entre esses fatores. O baixo desempenho pode também estar relacionado a outros fatores, como a carência de estratégias para resolver a situação, a natureza da tarefa e a demanda cognitiva excessiva da questão para uma dada capacidade mental, entre outros. 


\section{O desempenho nas questões da prova}

As análises dos resultados estão organizadas em consonância com as questões que o estudo propõe-se a responder. Essas análises permitiram atender ao objetivo geral da pesquisa: revelar aspectos essenciais do conhecimento profissional da Didática Geral mobilizados pelos futuros professores para responder situações-problema da atividade de ensino no contexto na prova de Didática Geral de um concurso para professor.

A tabela 2 apresenta informações sobre a primeira questão do estudo: qual o desempenho dos futuros professores na prova?

Tabela 2 - Desempenho/acertos dos candidatos por questões da prova

\begin{tabular}{c|c|c|c|c|c}
\hline Questão & $\begin{array}{c}\text { Quantidade } \\
\text { de respostas } \\
\text { no gabarito }\end{array}$ & \%Acertos & Questão & $\begin{array}{c}\text { Quantidade } \\
\text { de respostas } \\
\text { no gabarito }\end{array}$ & \% Acertos \\
\hline Questão 01 & 2447 & $20.0 \%$ & Questão 06 & 5213 & $42.6 \%$ \\
\hline Questão 02 & 6882 & $56.3 \%$ & Questão 07 & 2716 & $22.2 \%$ \\
\hline Questão 03 & 4025 & $32.9 \%$ & Questão 08 & 5261 & $43.0 \%$ \\
\hline Questão 04 & 6521 & $53.3 \%$ & Questão 09 & 6691 & $54.7 \%$ \\
\hline Questão 05 & 2002 & $16.4 \%$ & Questão 10 & 7217 & $59.0 \%$ \\
\hline
\end{tabular}

Fonte: UFRN - COMPERVE (2017).

Chama a atenção o precário desempenho dos candidatos no conjunto das questões da prova. Os acertos atingem uma amplitude que varia entre $16.4 \%$ e $59 \%$ de acertos, incidindo majoritariamente no quadrante dos menores valores, isto é, abaixo da média de $50 \%$ de acertos. Na verdade, é preocupante o fato de, no conjunto de candidatos submetidos a essa prova, 12.231, não se chegar a um desempenho de mais de $60 \%$ de acerto em cada uma das 10 questões demandadas.

De maneira mais detalhada, observa-se as questões com percentual de acertos mais baixos (Q1 - 20\%; Q3 - 32,9\%; Q5 - 16,4\% e Q7 - 22,7\%). Nestas, as habilidades requeridas eram:

a) identificar características da Didática Geral segundo as Tendências Pedagógicas;

b) caracterizar o currículo escolar e reconhecer características do conhecimento escolar;

c) analisar critérios para a escolha dos conteúdos no currículo e diferenciar tipos de conteúdos;

d) relacionar características da avaliação da aprendizagem com as tendências pedagógicas segundo os fundamentos da Teoria Histórico-Cultural de Vygotsky. 
As quatro questões com os melhores desempenhos (Q2-56,3\%; Q4 - 53,3\%; Q9 -54,7\%; Q10 - 59\%) sequer chegam a 60\% de acerto, um resultado muito abaixo do esperado. Estas tratam das seguintes habilidades:

a) reconhecer as contribuições da Sociologia, da Antropologia, da Psicologia, da Política da Filosofia à Didática Geral;

b) identificar características dos objetivos de ensino;

c) relacionar características da avaliação da aprendizagem com as Tendências Pedagógicas;

d) caracterizar aspectos essenciais do planejamento de ensino.

Duas questões se concentram na faixa dos $40 \%$ de acertos (Q6 - $42.6 \%$ e a Q8 -43\%) e se reportam às habilidades de:

a) identificar a relação dos métodos de ensino com os conteúdos de ensino;identificar critérios de escolha de métodos de ensino;

b) reconhecer características das atitudes e valores e sua formação no currículo escolar.

$\mathrm{Na}$ Tabela 3, temos outro indicador do domínio do conhecimento profissional avaliado na prova: a quantidade de candidatos segundo o número de questões respondidas corretamente. Essa informação integra e complementa os resultados em análise.

Tabela 3 - Número de acertos dos candidatos na prova

\begin{tabular}{c|c|c}
\hline Número de acertos & Número de candidatos & $\begin{array}{c}\text { Percentuais de candidatos } \\
\mathbf{( \% )}\end{array}$ \\
\hline 0 & 189 & $1.5 \%$ \\
\hline 1 & 793 & $6.5 \%$ \\
\hline 2 & 1628 & $13.3 \%$ \\
\hline 3 & 2299 & $18.8 \%$ \\
\hline 4 & 2456 & $20.1 \%$ \\
\hline 5 & 2060 & $16.8 \%$ \\
\hline 6 & 1487 & $12.2 \%$ \\
\hline 7 & 870 & $7.1 \%$ \\
\hline 8 & 378 & $3.1 \%$ \\
\hline 9 & 65 & $0.5 \%$ \\
\hline 10 & 6 & $0.0 \%$ \\
\hline Total & 12231 & $100.0 \%$ \\
\hline
\end{tabular}

Fonte: UFRN - COMPERVE (2017). 
Os acertos, quando distribuídos numa escala de zero a dez, deixam ainda mais evidente a concentração de candidatos com 3 (2299 - 18.8\%), 4 (2456 - 20.1\%) e 5 acertos (2060 - 16.8\%), totalizando $55,7 \%$ dos candidatos.

Ou seja, os candidatos à uma vaga para inserção na docência apresentaram um baixo domínio dos conhecimentos da Didática Geral avaliados na prova, situação que nos remete à identificação dos erros mais recorrentes nas dez questões. Estes são expressão do não domínio de conhecimentos que se julgam importantes, como recursos cognitivos a serem mobilizados na futura prática profissional.

\section{Erros, dificuldades de aprendizagem como expressão do conhecimento profissional da Didática Geral}

As análises dos distratores, segundo as alternativas mais selecionadas pelos candidatos, permitem-nos identificar e caracterizar erros que revelam dificuldades de aprendizagem e, consequentemente, evidenciam um estado dado dos conhecimentos profissionais da Didática Geral dos futuros professores e podem ser relacionados à formação inicial. A Tabela 4 apresenta os erros mais frequentes identificados nas análises.

Tabela 4 - Erros mais frequentes indicados

\begin{tabular}{l|c}
\hline \multicolumn{1}{c|}{ Erros } & $\mathbf{\%}$ \\
\hline $\begin{array}{l}\text { Considerar o planejamento e a instrumenta- } \\
\text { lização do ensino como objetos de estudo da } \\
\text { Didática Crítica }\end{array}$ & 50.8 \\
\hline $\begin{array}{l}\text { Atribuir ao currículo escolar uma organi- } \\
\text { zação em percursos formativos individuais } \\
\text { como forma de atender a contextualização } \\
\text { dos conteúdos e as aprendizagens flexíveis }\end{array}$ & 41.8 \\
\hline $\begin{array}{l}\text { Separar a assimilação dos conceitos da for- } \\
\text { mação e desenvolvimento de procedimentos }\end{array}$ & \\
\hline $\begin{array}{l}\text { Considerar a organização dos conteúdos no } \\
\text { currículo como exclusiva, do singular para o } \\
\text { geral }\end{array}$ & 39.5 \\
\hline $\begin{array}{l}\text { Considerar que, durante todo o processo de } \\
\text { internalização da atividade, a aprendizagem } \\
\text { deve ser baseada no método de trabalho em } \\
\text { grupo, segundo as ideias de Vygotsky }\end{array}$ & 25.7 \\
\hline $\begin{array}{l}\text { Considerar a informação como o fator deter- } \\
\text { minante na formação de atitudes }\end{array}$ & \\
\hline
\end{tabular}

Fonte: UFRN - COMPERVE (2017). 
Foram seis os tipos de erros identificados, segundo respectivas incidências. Um dos que mais se destaca nas respostas (50.9\%) é o que considera "o planejamento e a instrumentalização do ensino como objetos de estudo da Didática Crítica”. Veiga (1989, p. 75) ressalta que a Didática Crítica se situa no campo da Pedagogia Crítica.

Pouco mais da metade dos futuros professores associa ao objeto de estudo da Didática Crítica o planejamento e a instrumentalização do ensino, o que revela uma acentuada dificuldade nesse conteúdo. Na opinião de Libâneo (2013), a Didática não deve ser reduzida a uma questão instrumental, embora seja esse também um de seus objetivos.

Para Libâneo (2002), a Didática Crítica surge, no Brasil, no início dos anos 1980, preocupada em levar os professores a vincularem o ensino às realidades sociais, seja entendendo os conteúdos como cultura crítica, seja relacionando-os aos saberes do cotidiano.

Carranza (2012) entende a Didática Crítica como um conjunto de proposições filosóficas, científicas, tecnológicas e metodológicas, de enfoque crítico e comunicativo, de caráter histórico-cultural, que, em contextos geográficos e históricos dados, integram-se para mediar processos educativos transformadores e emancipatórios, em função das necessidades sociais, superando todo fator de alienação e opressão.

A Didática Crítica supera a visão da instrumentalização de ensino para focar o espaço de reflexão crítica das finalidades da educação. Por isso, instrumentalizar o ensino não é seu principal objeto de estudo. Numa visão tecnicista, a instrumentalização diz respeito ao uso de técnicas por meio das quais seria possível atingir os objetivos propostos para o ensino. Confrontando essa abordagem, temos as reflexões filosóficas, éticas, políticas, sociológicas que são parte do objeto da Didática Crítica voltada para educar os estudantes como cidadãos críticos. Esse enfoque procura superar o intelectualismo formal presente na Didática Tradicional e a visão instrumental do tecnicismo.

Outro erro bem expressivo (41,8\%) identificado nas respostas dos candidatos foi atribuir ao currículo escolar uma organização em percursos formativos individuais como forma de atender à contextualização dos conteúdos e as aprendizagens flexíveis". Nesse entendimento, o conhecimento profissional sobre o projeto pedagógico e o currículo escolar representa um conhecimento essencial no campo da Didática Geral, pois são eles que subsidiam o planejamento e, consequentemente, a prática pedagógica.

Os candidatos, em grande medida, admitiram que o currículo deve ser organizado em percursos formativos individuais, de forma aberta e contextualizada, para respeitar as diversidades presentes na escola. No entanto, a literatura ressalta que o projeto pedagógico e o currículo, como construções sociais, devem respeitar a dialética do social e do individual, como está explicitado nas Diretrizes Curriculares para o Ensino Fundamental de 9 (nove) anos (BRASIL, 2001). 
A problemática dos conteúdos escolares é um tema relevante na Didática Geral. A análises na tabela 4 mostra que o erro de 39,5\% dos candidatos se podem associar a "separar a assimilação dos conceitos da formação e do desenvolvimento de procedimentos". Essa dicotomia se revela no pensamento de muitos professores, quando não relacionam, de forma adequada, os conteúdos conceituais dos procedimentais. No entendimento de Talízina (2000), saber significa saber fazer algo. Segundo a autora, o domínio do conceito ocorre quando sabe-se usar e aplica-lo como parte de ações para resolver determinadas situações-problema.

Na opinião de Núñez (2009) os conteúdos conceituais e os procedimentais, ou seja, conceito e ação, formam uma unidade dialética. Por isso, no planejamento de ensino, um dos princípios didáticos é a definição das ações mais adequadas nas quais se assimilam e dominam os conteúdos conceituais.

Outro erro relacionado aos conteúdos de ensino foi "considerar a organização dos conteúdos no currículo como exclusiva, do singular para o geral", cometido por $25,7 \%$ dos candidatos. A organização dos conteúdos que respondem a uma ou outra finalidade educacional, na opinião de Davidov (1988), influencia o tipo de pensamento que pode ser estimulado: teórico ou empírico. A organização dos conteúdos, de forma exclusiva, do singular para o geral, caracteriza o que Davidov (1988) chama de mecanismo da generalização empírica, que favorece o pensamento empírico. A organização dos conteúdos de ensino deve considerar a dialética entre o singular e o geral, ou seja, o caminho do geral para o particular.

Davidov (1988) destaca que a assimilação dos conhecimentos de caráteres geral e abstrato precede a assimilação dos conhecimentos mais particulares e concretos, que não devem constituir a única base dos primeiros. Considera ainda que o desenvolvimento do pensamento científico supõe também generalizações teóricas numa relação dialética entre abstrato e concreto, entre geral e singular.

Na Didática Desenvolvimentista (LIBÂNEO, 2013), numa perspectiva Sistêmica Dialética do Conteúdo (NÚÑEZ, 2009), os conteúdos podem ser organizados também do geral para o particular, ou seja, do abstrato para o concreto, o que favorece o desenvolvimento do pensamento teórico (DAVIDOV, 1988).

Os conhecimentos da Psicologia da Educação se integram à base de conhecimentos da Didática Geral como um dos fundamentos para a compreensão dos processos de ensino e aprendizagem. Nessa abordagem, os conhecimentos da Psicologia Educacional são necessários para a resolução de certas situações-problema que dizem respeito aos conhecimentos postulados pela Teoria Histórico Cultural de L.S. Vygostsky, conteúdos nos quais os candidatos revelaram acentuada dificuldade. O erro nessa questão foi considerar que "durante todo o processo de internalização da atividade, a aprendizagem deve ser baseada no método de trabalho em grupo, segundo as ideias de Vygotsky". O estudo identificou $46,3 \%$ de erros concentrados nesse item.

Vygotsky (2000) enuncia como um elemento essencial de sua teoria a Lei Genética de Desenvolvimento Cultural, o que justifica o caráter social da aprendizagem, mas também a função da autonomia intelectual, como explica Núñez (2009). A 
de internalização dos conteúdos culturais deve ser organizada num processo pautado pelas interações com os colegas e com o professor, agente cultural e educador, para processos de maior independência cognitiva. A internalização (assimilação) de um conteúdo deve organizar-se partindo de atividades colaborativas (plano interpsicológico) para a autonomia intelectual (plano intrapsicológico).

Nessa perspectiva, situa-se a Zona de Desenvolvimento Próximo (ZDP), que revela a passagem do desenvolvimento potencial do aluno (o que pode ser feito com a ajuda do outro) para um desenvolvimento real (determinado pela possibilidade de solução da tarefa com autonomia). Dessa forma, a aprendizagem pode resultar em desenvolvimento intelectual. Para Talízina (2000), a teoria de ensino deve estar pautada no estudo das regularidades da transformação dos fenômenos da consciência social em fenômenos da consciência individual.

As contribuições teóricas do enfoque Histórico-Cultural tem dado lugar à Didática Desenvolvimentista (LIBÂNEO, 2013; NÚÑ̃Z, 2009). Trata-se da orientação do ensino na apropriação ativa e criativa da cultura, favorecendo o desenvolvimento do aperfeiçoamento constante da autonomia e da autodeterminação, em estreita união com os processos de socialização, compromisso e responsabilidade para com a sociedade. $\mathrm{O}$ ensino, então, organiza-se a partir dos níveis de desenvolvimento atual e potencial dos estudantes, o que leva a níveis qualitativamente superiores de desenvolvimento integral destes.

As dificuldades de aprendizagem aqui constatadas têm sido identificadas em várias pesquisas, e referem-se, dentre outras, às formas como a teoria é ensinada nos cursos de graduação para formação de professores (RASIA, 2015; FARIÑAS, 2015), o que evidencia diversas interpretações da obra de Vygotsky, nas quais seus fundamentos filosóficos e epistemológicos se esvaziam (DUARTE, 2000; NÚÑEZ, 2009; PRESTES, 2010).

A formação de atitudes e valores são finalidades da educação no contexto escolar, e objeto de preocupação da Didática Geral. Na prova, avaliou-se o conhecimento profissional sobre esse conteúdo, e identificou-se que o erro nessa temática $(31,1 \%)$ está em considerar a informação como o fator determinante na formação de atitudes.

Ressalta-se que, por intermédio do ensino é preciso potencializar não só a aprendizagem de conhecimentos e procedimentos, mas também o desenvolvimento integral dos estudantes, criando-se situações educativas para garantir unidade entre o cognitivo e o afetivo (VYGOTSKY, 2000), a fim de desenvolver atitudes e valores, como finalidades da educação. Assim, é objetivo fundamental da escola desenvolver plenamente a personalidade dos estudantes, ou seja, seu desenvolvimento integral, que supõe as dimensões intelectual, corporal, social, afetivo e ético-moral.

A escola, de forma geral, enfoca a dimensão cognitiva da personalidade dos estudantes, pelo que não atinge a meta educativa principal. Nesse sentido, o conhecimento profissional dos professores sobre esse assunto é essencialmente estratégico. 
A informação é um elemento essencial no processo de formação das atitudes, mas torna-se insuficiente. As atitudes são componentes dos conteúdos que dizem respeito às disposições, indicações, preferências do indivíduo em relação a objetos, fatos, assuntos ou pessoas; e são de natureza interna. (OLIVEIRA; CHADWICK, 2007).

Para Baxter (2003), as atitudes são construtos aos quais são atribuídas as capacidade de explicar e prever comportamentos sociais e apresentam uma relação estreita com outros conceitos, como o de valores.

Em relação às informações no processo de formação de atitudes na escola, os Parâmetros Curriculares Nacionais para os terceiro e quarto anos do Ensino Fundamental afirmam:

\begin{abstract}
A informação é necessária para poder concretizar uma atitude de forma eficaz, mas é verdade também que somente a informação não é suficiente para ensinar valores e atitudes. Existem fatores culturais importantes que determinam a impossibilidade de existência de uma relação direta entre informação e mudança de atitudes; é fundamental considerá-los na prática de ensino e na aprendizagem de valores (BRASIL, 1998, p. 78).
\end{abstract}

\title{
Conclusões
}

O estudo possibilitou uma discussão sobre o desempenho, os erros e dificuldades de aprendizagem que podem ser associados aos conteúdos avaliados na prova. Nesse sentido, constatou-se desempenho baixo para $60 \%$ dos conteúdos. Os erros mais frequentes revelaram dificuldades nos fundamentos da aprendizagem baseados nas ideias de Vigotsky, no objeto de estudo da didática crítica, na organização dos conteúdos do currículo, na formação de atitudes na escola. Estas podem estar associadas à formação inicial, à qual é preciso que se dê mais atenção.

Certamente o conhecimento profissional não pode ser uma simples aplicação da teoria numa situação de avaliação. Atribuir sentido à teoria em função dos problemas práticos, na atividade de ensino, é um processo complexo que exige estabelecimento de relações epistemológicas novas, criando significados originais e transformando o conhecimento em saberes.

Os conhecimentos da Didática Geral são condições necessárias, mas não suficientes para o ensino de qualidade; são eficientes na medida que sirvam para fundamentar as tomadas de decisões da prática pedagógica, como Shulman (1987) alerta: a compreensão sozinha não é suficiente. Para o autor, a utilidade de cada conhecimento repousa sobre seu valor para julgamento e ação.

Apesar de limitações inerentes à análise de uma prova escrita com questões objetivas, os resultados aqui sistematizados permitem identificar os (des) conhecimentos que são revelados e ou mobilizados por um número significativo de futuros professores quando submetidos a situações didáticas problematizadas. 


\section{Referências}

BÁXTER PÉREZ, E. Cuándo y como educar en valores? La Habana: Editorial Pueblo y Educación, 2003.

BRASIL. Conselho Nacional de Educação. Diretrizes Curriculares Nacionais para a Formação de Professores da Educação Básica, em nível superior, curso de licenciatura, de graduação plena. Diário Oficial [da] República Federativa do Brasil, seção 1, p. 31, 18 de janeiro de 2001. Disponível em:< http://portal.mec.gov.br/cne/arquivos/pdf/009.pdf>. Acesso em: 29 jul. 2017.

BRASIL. Instituto Nacional de Estudos e Pesquisas Educacionais Anísio Teixeira - INEP. Relatório Pedagógico ENEM 2011-2012. Brasília: INEP, 2015.

CANDAU, V. (org). Didática. Questões Contemporâneas. Rio de Janeiro: Editora Forma e Ação. 2009.

CARRANZA, J. E. Pedagogia y Didáctica Crítica. Integra Educativa. n.4, vol II, p. 75-92. 2012.

DAVÍDOV, V. La enseñanza escolar y el desarrollo psíquico: investigación psicológica teórica e experimental. Moscú: Editorial Progreso, 1988. p. 3-277.

DUARTE, N. Vigotski e o "aprender a aprender": crítica às apropriações neoliberais e pósmodernas da teoria vigotskiana. Campinas: Autores Associados, 2000.

FARIÑAS, G. L. Lo emblemático en el enfoque Histórico-Cultural: apuntes para una práxis de rigor. Revista Amazônica. Humaitá, v. 12, n. 2, p. 102-134, Jul./Dez. 2013.

FREIRE, P. Pedagogia da autonomia. Saberes necessários à prática educativa. 15. ed. São Paulo: Editora Paz e Terra, 2000.

GATTI, B. A. Formação de professores no Brasil: características e problemas. Educação \& Sociedade. Campinas, v.31, n. 113, p. 1355-1379. Out/dez. 2010.

GAUTHIER, C. et al. Por uma teoria da Pedagogia. Pesquisas contemporâneas sobre o saber docente. Ijuí-RS: Editora INIJUI, 1998.

HALADYNA, T. Developing and Validating Multiple Choice Test Stems. 3. ed. Mahwah: Lawrence Earlbaum Associates, 2004.

LIBÂNEO, J.C. Didática. Velhos e novos temas. Goiania: Edição do Autor, 2002. Disponível em: <http://nead.uesc.br/arquivos/Biologia/scorm/Jose_Carlos_Libaneo_-_Livro_Didatica_Lib_oneo_1_.pdf >>. Acesso em: 20 jan. 2017.

LIBÂNEO, J.C. A aprendizagem escolar e a formação do professor na perspectiva da psicologia histórico-cultural e da teoria da atividade. Educar. Curitiba, v.2, n. 24, p. 113-147, Jul./ Dez. 2004.

LIBÂNEO, J.C. A integração entre Didática e Epistemologia das disciplinas: uma via para a renovação dos conteúdos da Didática. In: DALBEN, A. et al (orgs). Convergências e tensões no campo da formação e do trabalho docente: Didática, formação de professores e trabalho docente. Belo Horizonte: Autêntica, 2010, p. 81-105.

LIBÂNEO, J.C. Panorama do ensino da Didática, das metodologias específicas e das disciplinas conexas nos cursos de Pedagogia: repercussões na qualidade da formação profissional. In: LONGAREZI, A. M.; PUENTES, R. V. (orgs.). Panorama da Didática: ensino, prática e pesquisa. São Paulo: Papirus, 2011, p. 11-50.

LIBÂNEO, J.C. A didática desenvolvimental e o currículo de formação profissional de professores: a articulação entre o conhecimento pedagógico-didático e o conhecimento disciplinar. [s.d.] Disponível em: $<$ https://scholar.google.com.br/scholar?rlz= 1C1AVNG_enBR684BR684\&um=1\&ie=UTF8\&lr\&q=related:rhOWi3oCm1TYzM:scholar.google.com $/>$. Acesso em: 23 ago. 2013. 
LONGAREZI, A. M; PUENTES, R. (Orgs.). Panorama da Didática: ensino, prática e pesquisa. São Paulo: Papirus, 2011.

MARCELO, C. G. Formalidade e informalidade no processo de aprender a ensinar. In: PUENTES, Roberto Valdés et al. (orgs). Ensino Médio: estado atual, políticas e formação de professores. Uberlândia: EDUFU, 2012. p. 181-204.

NÚÑEZ, I. B. Vygotsky, Leontiev, Galperin: formação de conceitos e princípios didáticos. Brasília: Liber Livro, 2009.

NÚÑEZ, I. B.; RAMALHO, B. L. As provas de química e de Biologia de Vestibulares da UFRN: estudo de erros e dificuldades de aprendizagem. Natal: EDUFRN, 2012.

OLIVEIRA, M. K. Vygotsky: alguns equívocos na interpretação de seu pensamento. Cadernos de Pesquisa. n. 81, p. 67-69, SP, Fundação Carlos Chagas, 1992.

OLIVEIRA, J. B; CHADWICK, C. Aprender a ensinar. Belo Horizonte: Alfa Educativa LTDA. 2007.

PASQUALI, L. Psicométrica. Teoría dos testes na Psicologia e na Educação. Rio de Janeiro: Editora Vozes, 2013.

PIMENTA, S. G. A didática como mediação na construção da identidade do professor. Uma experiência de ensino e pesquisa na licenciatura. In: ANDRÉ, M.E.D.A.; OLIVEIRA, M. R. (orgs). Alternativas do ensino de didática. Campinas: Papirus, 1997.

PRESTES, Z. R. Quando não é quase a mesma coisa. Análise de traduções de Lev. Semionovich Vigotski no Brasil. Repercussão no campo educacional. Tese de Doutorado. Programa de Pós-Graduação em Educação. Faculdade de Educação. Universidade de Brasilia (UnB), 2010. Disponível em:< https://www.cepae.ufg.br/up/80/o/ZOIA_PRESTES_-_TESE. pdf?1462533012>. Acesso em: 24 set. 2017.

PUENTES, R. V et al. Profissionalização dos professores: conhecimentos, saberes e competências necessários à docência, Educar, Curitiba, n. 34, p. 169-184, 2009.

RAMALHO, B. L.; NÚÑEZ, I. B; GAUTHIER, C. Formar o professor: profissionalizar o ensino. Perspectivas e desafíos. Porto Alegre: Sulinas, 2004.

RASIA, M. G. R. A Psicologia Histórico-Cultural na formação docente. Ensino em Revista. v. 22, n. 1, p. 183-195, Jan-Jun, 2015.

SALAZAR, D. F. Didáctica, interdisciplinariedad y trabajo científico en la formación del profesor. In: FERNANDEZ, Fátima Addine et al (Orgs.). Didáctica: teoría y práctica. Ha Habana: Editorial Pueblo y Educação, 2004, p. 117-153.

SHULMAN, L. S. "Knowledge and Teaching: Foundations of the New Reform”. Harvard Educational Review. n. 57, v. 1, p. 1-22, 1987.

TALÍZINA, N. Manual de Psicologia Pedagógica. San Luís de Potosí: Universidade Autônoma de San Luís de Potosí, 2000.

TARDIF, M. Saberes docentes e formação profissional. 3. ed. Petrópolis-RJ: Editora. Vozes, 2003.

VEIGA, I. P. A. A prática pedagógica do professor de didática. Campinas: Papirus, 1989.

VEIGA, I. P. A. (Org.). Repensando a didática. 23. ed. São Paulo: Papirus, 2005.

VIGOSTSKY, L. S. A construção do pensamento e da linguagem. Trad. Paulo Bezerra. São Paulo: Martins Fontes, 2000

ZABALZA, M.A. Fundamentación de la Didáctica y del conocimiento. In: MEDINA, A.; SEVILLANO, M.I. Didáctica. Madrid: UNED, v.1, 1990, p. 85-220. 
* Professor doutor do Centro de Educação da Universidade Federal do Rio Grande do Norte, Natal, Rio Grande do Norte, Brasil.

** Professora doutora do Centro de Educação da Universidade Federal do Rio Grande do Norte, Natal,

Rio Grande do Norte, Brasil.

\section{Correspondência}

Isauro Beltrán Núñez - Universidade Federal do Rio Grande do Norte, Centro de Educação, Departamento de Práticas Educacionais e Currículo. Programa de Pós Graduação em Educação - Lagoa Nova. CEP: 59072-970. Natal, Rio Grande do Norte, Brasil.

E-mail: isaurobeltran@yahoo.com.br - betania.leite@terra.com.br

Recebido em 03 de março de 2018

Aprovado em 22 de maio de 2018 